\title{
Pengembangan Media Pembelajaran Alignment pada Pulley dan Kopling Menggunakan Metode Cahaya Laser dan Dial Indicator pada Mata Kuliah Praktik Alignment
}

\author{
Aminuddin $^{1^{*}}$ \& Muhammad Nur ${ }^{2}$ \\ ${ }^{1 *}$ Program Studi Perawatan dan Perbaikan Mesin, ${ }^{2}$ Teknik Mekatronika \\ Politeknik Bosowa \\ *Corresponding Author. Email: aminuddin@politeknikbosowa.ac.id
}

\begin{abstract}
The purpose of this study was to develop alignment learning media on pulleys and couplings using laser light methods and dial indicators in alignment practice courses. This research method used research and development (R\&D). The subjects of this study were 16 third semester students. The instruments used were questionnaires and tests. The data analysis technique used in this research was statistical analysis with t-test. The results of this study indicate that the media expert's validity test scores 4 and this shows that the learning media is made attractive and effective in its use, the results of the pre-test and post-test scores, namely that there is an increase in student scores from an average value of 48.5 to 79.6. or if in percentage there is an increase of $63.9 \%$ of all student grades. The test results using SPSS where the mean value of the post test was 79.69> of the pre test was 48.75 , while in the paired sample correlations the value was Sign. $0.000<$ than 0.05 , it can be said that there is a relationship between the Pre Test variable with the Post Test and Paired Samples Test variables of $0.000<0.05$.
\end{abstract}

\begin{abstract}
Abstrak: Tujuan penelitian ini adalah untuk mengembangkan media pembelajaran alignment pada pulley dan kopling menggunakan metode cahaya laser dan dial indicator pada mata kuliah praktik alignment. Metode penelitian ini menggunakan research and development $(R \& D)$. Subjek penelitian ini adalah mahasiswa semester 3 yang berjumlah 16 orang. Instrumen yang digunakan berupa angket dan tes. Teknik analisis data penelitian ini menggunakan analisis statistik dengan uji-t. Hasil penelitian ini menunjukkan bahwa uji validitas ahli media didapatkan nilai 4 dan ini menunjukkan media pembelajaran yang dibuat menarik dan efektif dalam penggunaannya, hasil dari nilai pre tes dan post tes yakni terdapat peningkatan nilai mahasiswa dari nilai rata-rata 48,5 menjadi 79,6 atau jika di persentasekan ada peningkatan sebesar 63,9\% dari seluruh nilai mahasiswa. Hasil uji menggunakan SPSS dimana nilai yang rata-rata post test $79.69>$ dari pre test sebesar 48.75, sedangkan pada paired sample correlations nilai Sign. $0.000<$ dari 0.05 maka dapat dikatakan ada hubungan antara variabel pre test dengan variabel post test dan Paired Samples Test Sebesar $0.000<0.05$.
\end{abstract}

\section{Article History}

Received: 04-12-2020

Revised: 23-02-2021

Accepted: 21-04-2021

Published: 07-06-2021

\section{Key Words:}

Learning Media, Alignment, Laser, Dial Indicator.

\section{Sejarah Artikel \\ Diterima: 04-12-2020 \\ Direvisi: 23-02-2021 \\ Disetujui: 21-04-2021 \\ Diterbitkan: 07-06-2021}

\section{Kata Kunci:}

Media Pembelajaran, Alignment, Laser, Dial Indicator.

How to Cite: Aminuddin, A., \& Nur, M. (2021). Pengembangan Media Pembelajaran Alignment pada Pulley dan Kopling Menggunakan Metode Cahaya Laser dan Dial Indicator pada Mata Kuliah Praktik Alignment. Jurnal Kependidikan: Jurnal Hasil Penelitian dan Kajian Kepustakaan di Bidang Pendidikan, Pengajaran dan Pembelajaran, 7(2), 408-416. doi:https://doi.org/10.33394/jk.v7i2.3197

https://doi.org/10.33394/jk.v7i2.3197

This is an open-access article under the CC-BY-SA License.

\section{Pendahuluan}

Mutu pendidikan yang baik merupakan salah satu unsur yang sangat penting dalam upaya peningkatan kualitas sumber daya manusia. Undang-undang Sistem Pendidikan Nasional No. 20 tahun 2003 Bab I ketentuan umum, Pasal I berbunyi, "Pendidikan adalah usaha sadar dan terencana untuk mewujudkan suasana belajar dan proses pembelajaran agar peserta didik secara aktif mengembangkan potensi dirinya untuk memiliki kekuatan spritual 
keagamaan, pengendalian diri, kepribadian, kecerdasan, akhlak mulia, serta keterampilan yang diperlukan dirinya, masyarakat, bangsa dan negara" (PP No 20 Tahun 2003).

Berdasarkan isi undang-undang diatas, satu hal yang perlu menjadi perhatian adalah suasana belajar. Masalah tersebut adalah hal yang paling sering dihadapi mahasiswa sehingga masih banyak yang belum dapat mencapai prestasi belajar yang memuaskan karena suasana belajar yang kurang menarik. Terkait prestasi belajar, sangat banyak faktor yang dapat mempengaruhi diantaranya: faktor internal (dari dalam) dan ekstrenal (dari luar). Faktor intern meliputi faktor fisik dan faktor psikis. Faktor fisik seperti keadaan kesehatan, keadaan tubuh. Dan faktor psikis seperti perhatian, minat, bakat, dan kesiapan. Sedangkan faktor eksternal yaitu faktor sekolah seperti kurikulum, metode mengajar, interaksi antarsiswa, disiplin di sekolah, alat pelajaran, keadaan gedung, dan perpustakaan (Ayuning Raresik, 2016).

Politeknik Bosowa adalah pendidikan tinggi vokasi yang berbasis industri dan memiliki tujuan untuk meningkatkan prestasi mahasiswa dalam proses belajar serta mendekatkan mahasiswa dengan dunia industri, ketersediaan media pembelajaran yang relevan dengan mata kuliah dan kebutuhan industri adalah sebuah kewajiban, pendidikan vokasi merupakan pendidikan yang ditujukan dalam persiapan pemenuhan individu dalam rangka memasuki dunia kerja sesuai kebutuhan industri (Sukoco, 2019). Dari fakta yang terjadi pada mata kuliah praktik alignment, proses belajar mengajar yang dilakukan masih bersifat konvensional dan sangat sederhana.

Kemajuan dan perkembangan media pembelajaran menuntut pengajar untuk dapat menjadikan suasana belajar yang menarik. Dengan adanya media pembelajaran membawa dampak positif terhadap proses belajar yang dilakukan, membuat susana belajar menjadi sangat menarik apalagi lagi pada mata kuliah praktek. Media pembelajaran merupakan segala sesuatu yang dapat digunakan untuk menyalurkan pesan pengirim kepada penerima, sehingga dapat merangsang pikiran, perasaan, perhatian, dan minat peserta didik untuk belajar (Tafonao, 2018).

Perkembangan model pembelajaran pada saat ini, menuntut pengajar atau dosen untuk lebih kreatif dalam melaksanakan proses belajar mengajar, pengajar diharapkan mampu menciptakan suasana belajar yang nyaman, menarik, santai dan membuat mahasiswa mampu memahami materi dengan cepat. Media pembelajaran menjadi sebuah solusi terbaik untuk mendukung tercapainya tujuan dari proses belajar mengajar serta prestasi belajar. Media merupakan salah satu faktor penentu keberhasilan pembelajaran. Melalui media proses pembelajaran bisa lebih menarik dan menyenangkan, misalnya peserta didik yang memiliki ketertarikan terhadap warna maka dapat diberikan media dengan warna yang menarik (Rudi Susialana, 2011)

Media pembelajaran yang menarik adalah media pembelajaran yang mampu memenuhi minimal empat kriteria diantaranya, Relevansi artinya sesuai kebutuhan, Menarik artinya mampu merangsang minat mahasiswa, Mudah dalam hal penggunaan serta pengoperasian dan Kebermanfaatan yaitu mahasiswa mampu memahami materi dengan cepat dan baik (Mulyatiningsih, 2013)

Praktik alignment pada poros dan pully yang dilakukan di politeknik bosowa masih menggunakan alat sederhana seperti bahan kayu atau besi panjang yang dianggap lurus, kondisi inilah yang membuat proses belajar mengajar praktik alignment cenderung membosankan, dari kondisi seperti inilah yang mendorong kami untuk membuat sebuah media pembelajaran pada mata kuliah praktik alignment yang mampu menjadikan mahasiswa merasakan kondisi yang nyaman, menarik, santai dan mudah memahami materi dalam proses belajar mengajar praktik. Pada proses pembelajaran, media pengajaran merupakan wadah dan 
penyalur pesan dari sumber pesan, dalam hal ini guru atau dosen, kepada penerima pesan, dalam hal ini siswa (Nunu M, 2012)

Alignment adalah suatu kegiatan yang meluruskan atau mensejajarkan dua sumbu poros hingga sentris (antara poros penggerak dengan sumbu poros yang digerakkan). Setiap poros yang berputar cenderung akan berputar pada garis sumbu masing-masing, kondisi inilah yang menimbulkan terjadinya misalignment. Sekitar $70 \%$ dari penyebab kerusakan mesin rotasi dikarenakan misalignment, yang dapat menyebabkan gaya yang berlebihan pada bearing, sehingga menyebabkan kerusakan bearing sebelum waktunya (Darmawan, 2016).

Misalignment dapat terjadi disebabkan mesin mengalami soft foot pada kaki-kaki mesin dan terjadi run out pada kopling dan poros mesin, yang dapat mengakibatkan terjadinya paralel misalignment dan angular misalingnment (Taufan irvan A, 2018). Sedangkan menurut (Dodi, 2018) Misalignment adalah kondisi penyimpangan dimana sumbu dari dua benda yang dikopel tidak dalam kondisi segaris, misalignment merupakan penyebab kegagalan yang sering terjadi pada mesin rotasi.

Kondisi Misalignment memiliki dampak berbahaya yang dimana kondisi tersebut dapat menyebabkan, Panas berlebih pada kopling, kelelahan material, keausan pada kopling roda gigi, keretakan pada poros, kerusakan bantalan dan getaran yang berlebih pada sebuah komponen. Misalignment adalah kondisi yang sangat tidak dibolehkan terjadi, karena misalignment merupakan penyebab utama terjadinya kerusakan mesin. Kita dapat menghemat pengeluaran jika mesin-mesin tidak terjadi misalignment (Lifetime Reliability Solution, 2012)

Media pembelajaran ini terfokus membahas misalignment yang terjadi pada poros atau kopling dan misalignment yang terjadi pada poros sejajar atau Pully. Terdapat tiga jenis misalignment yang terjadi pada poros selurus atau kopling, yaitu: Paralel, angular dan combinasi (Darto, Sudjatmiko, 2015). Sedangkan pada Pulley terdapat tiga jenis Misalingment yaitu Parallel misalignment, Horizontal angle misalignment dan offset misalignment (SKF Book, 2002).

Media pembelajaran Alignment pada pulley dan Kopling dengan metode cahaya laser dan dial indicator adalah gabung dua aktifitas yang dapat dilakukan pada satu alat, maka dari itu media ini dapat dikatakan sebagai media yang ekonomis dan efisien dari segi harga. Sebagai media pembelajaran sederhana menggunakan metode laser untuk mendeteksi misalignment adalah sebuah terobosan karena untuk saat ini alat yang serupa diproduksi oleh perusahaan besar dan memiliki harga yang sangat mahal. Sedangkan untuk metode dial indicator adalah pengembangan dari keterbatasan media yang terjadi di politeknik bosowa. Dengan alat ini menjadi angin segar untuk program studi perawatan dan perbaikan mesin dan politeknik bosowa karena capaiaan pembelajaran dapat dilakukan dengan sebuah alat dari hasil penelitian tersebut.

Sebagai media pembelajaran pada mata kuliah praktik alignment, media pembelajaran alignment pulli dan kopling dengan menggunakan metode laser dan dial indikator ini bertujuan untuk memberikan kemudahan mahasiswa dalam memahami materi mata kuliah praktik alignment serta dapat menambah kemampuan mahasiswa dalam melakukan proses alingment pada poros yang sejajar dan sesumbu.

\section{Metode Penelitian}

Penelitian ini termasuk jenis penelitian Research and Development (R\&D), merupakan metode penelitian yang digunakan untuk menghasilkan produk tertentu dan menguji keefektifan produk tersebut (Sugiyono, 2016). penelitian ini dilakukan dengan berbagai tahap dimulai dengan Analysis, Desain, Development, Implementation, dan 
Evaluation atau disingkat dengan ADDIE, ini dapat kita lihat diagram alir metode penelitian yang akan dilakukan.

Subjek dari penelitian ini adalah mahasiswa program studi perawatan dan perbaikan mesin Politeknik Bosowa angkatan 2019 semester 3 dengan jumlah populasi sebanyak 16 orang. Sedangkan untuk instrumen penelitian menggunakan angket dan lembar validasi ahli media serta penilaiaan hasil belajar atau ujian akhir mata kuliah praktik Alignment.

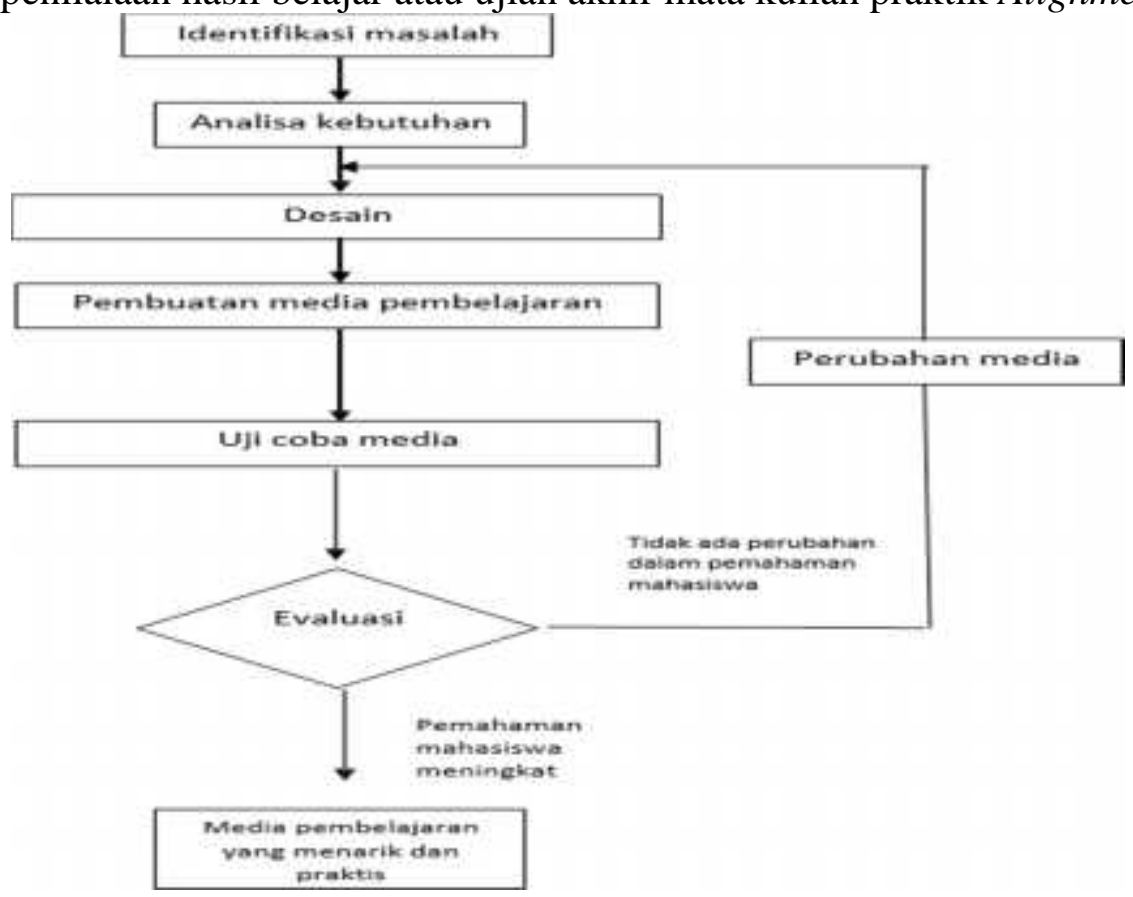

\section{Gambar 1. Diagram Alir Penelitian}

Pada indentifikasi yang dilakukan pada mata kuliah praktik alignment, permasalahan yang timbul adalah kondisi proses belajar yang terjadi dimana untuk kegiatan alignment pada poros, mahasiswa masih menggunakan mistar yang tidak terukur dan terstandarisasi, mistar tersebut dipotong dengan panjang sekitar $15 \mathrm{~cm}$, dan disaat dilakukan kegiatan alignment mistar tersebut diletakkan searah dengan poros dan dilihat secara visual apakah telah rata dengan poros atau belum. Sedangkan untuk alignment pully mahasiswa meletakkan mistar panjang yang terbuat dari besi atau kayu, kemudian diletakkan pada sisi pully selanjutnya dilihat secara visual apakah masih ada celah yang terjadi.

Sebelum pembuatan media pembelajaran, perlu dilakukan perancangan bentukbentuk yang akan digunakan sebagai media belajar dengan menggunakan software gambar dalam hal ini solidwork atau Autodesk untuk menentukan rancangan dari media pengajaran yang akan dibuat. Tahap pembuatan media pembelajaran alignment mengacu pada hasil dari perancangan yang telah dibuat sebelumnya, proses pembuatan media tersebut mengikuti bentuk dan ukuran yang telah direncanakan pada proses perancangan. Dalam pembuatan beberapa komponen media pembelajaran ini dilakukan dibeberapa lokasi, yaitu Politeknik Bosowa, PT. Semen Bosowa Maros dan beberapa bengkel. Tahap uji coba, media pembelajaran yang telah selesai dibuat akan diaplikasikan langsung dalam mata kuliah praktik alignment di prodi perawatan dan perbaikan mesin politeknik bosowa, pada penggunaan media nantinya dilihat dan dikumpulkan seluruh instrument berupa angket untuk validasi ahli media dan nilai tes mahasiswa. Setiap aspek atau keseluruhan aspek yang dinilai ditetapkan berdasarkan kriteria pengkategorian kualitas perangkat yang diadaptasi dari pengkategorian menurut (Azwar, 2013). 
Instrumen adalah semua alat yang digunakan untuk mengumpulkan, memeriksa, menyelidiki suatu masalah, mengolah, menganalisa dan menyajikan data-data secara sistematis serta objektif dengan tujuan memecahkan suatu persoalan atau menguji suatu hipotesis, instrumen penelitian merupakan alat bantu yang dipilih \& digunakan oleh peneliti dalam melakukan kegiatannya untuk mengumpulkan data agar kegiatan tersebut menjadi sistematis \& dipermudah olehnya (Suharsimi, 2016). Evaluasi media pembelajaran praktik alignment, nantinya akan dilakukan penilaiaan terhadap media apakah layak untuk digunakan berdasarkan kemudahan penggunaan, fungsi dan desain. Untuk melihat adannya peningkatan hasil belajar mahasiswa dilakukan pengumpulan data kuantitatif yang nantinya akan diolah dan dilakukan uji t pada aplikasi SPSS dari data tersebut akan memperlihatkan adanya peningkatan, dengan syarat Ho diterima apabila nilai signifikansinya $>0,05$ dan apabila nilai signifikansi yang diperoleh berada pada nilai $<0,05$ maka Ho ditolak atau dapat disimpulkan bahwa hasil belajar mahasiswa yang mengikuti mata kuliah praktik alignment tersebut tidak mengalami peningkatan hasil belajar secara signifikan.

\section{Hasil Penelitian dan Pembahasan}

\section{Analisis}

Kondisi yang terjadi dilapangan adalah hal yang sangat diperlukan untuk melakukan analisis, sehingga nantinya proses yang akan dilaksanan dapat berjalan dengan lancar dan menghasilkan sebuah penelitian yang berkualitas. Adapun yang akan dianalisa meliputi, kondisi lingkungan kampus, sumber belajar, dosen, dan mahasiswa, kondisi yang terjadi di Politeknik Bosowa makassar adalah kurangnya alat atau media pembelajaran yang memadai untuk digunakan dalam kegiatan belajar mengajar praktik, terkhusus mata kuliah praktik alignment sampai saat ini belum memiliki alat yang mampu menunjang kelancaran kegiatan praktik tersebut. Dalam pelaksanaanya apabila mahasiswa melakukan praktik alignment pulley mahasiswa menggunakan mistar panjang, sedangkan untuk alignment kopling mahasiswa menggunakan mistar yang dipotong sepanjang 15 centimeter, dengan media pembelajaran yang dihasilkan akan mengganti metode konvensional yang sebelumnya dilakukan, untuk praktik alignment pulley akan menggunakan sebuah alat yang akan memberikan informasi jika terjadi misalignment sedangkan alignment kopling akan menggunakan dial indicator.

\section{Desain}

Hasil dari analisis selanjutnya ketahap desain, untuk desain media terbagi kedalam beberapa komponen yang terdiri dari bebrapa komponen utama diantaranya adalah, rangka media pembelajaran, motor penggerak, reducer, kopling, Pulley. Adapun hasil rancangan ini sebagai berikut.
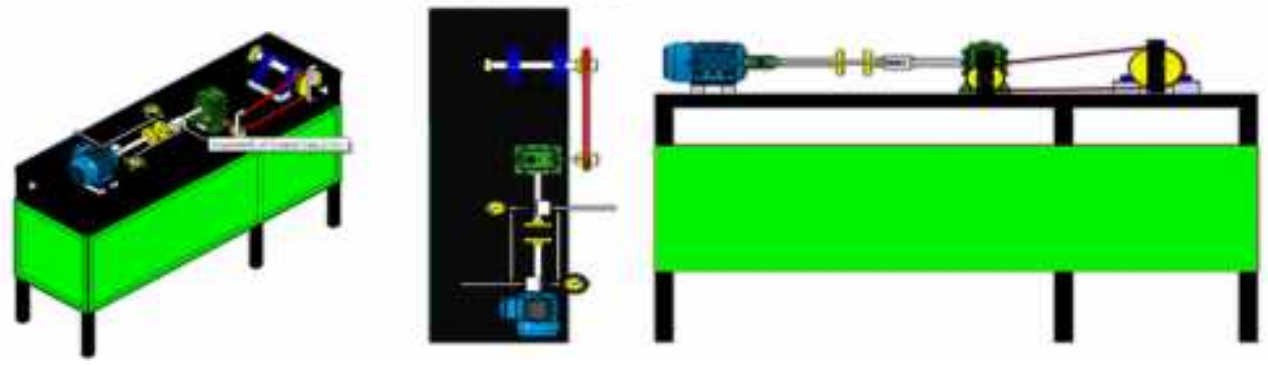

Gambar 2. Rancangan Desain media

Pada proses pembuatan media sepenuhnya mengacu pada rancangan desain yang telah dibuat diawal perencanaan pembuatan media dan hasil rancangan yang telah dibuat sangat identik 
dengan rancangan awal karena sepenuhnya mengacu pada rancangan tersebut, dibawah ini dapat kita lihat media pembelajaran yang telah dibuat.

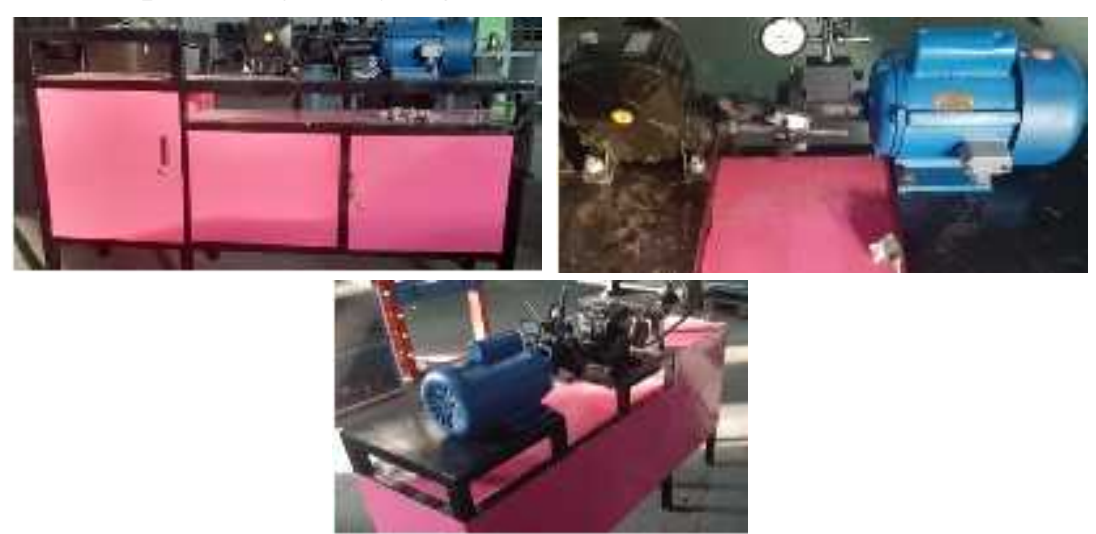

\section{Pengembangan}

\section{Gambar 3. Hasil Media Pembelajaran}

Pengembangan adalah langkah selanjutnya yang ditempuh setelah perancangan telah dilakukan, pada tahap ini media akan dilakukan beberapa aktifitas yang tujuannya untuk memberikan gambaran penggunaan media pembelajaran

a) Validasi ahli media, didalamnya terdapat lima poin pertanyaan dan terdapat dua komponen utama yaitu kemenarikan dan efektifitas media yang dibuat dan adapun nilai yang didapatkan dari dua orang ahli media.

Tabel 1. Hasil validasi ahli media

\begin{tabular}{|c|l|c|c|}
\hline \multicolumn{4}{|c|}{ Instrumen ahli media } \\
\hline Perangkat & Indikator & Penilaian & Kategori \\
\hline \multirow{3}{*}{ Media } & Kemanarikan & 4 & Sangat Valid \\
\cline { 2 - 4 } & Efektifitas & 4 & Sangat Valid \\
\cline { 2 - 4 } & Rata-rata & $\mathbf{4}$ & Sangat Valid \\
\hline
\end{tabular}

b) Penilaiaan Pre Tes dan Post Test, adalah penilaiaan prestasi belajar mahasiswa yang termasuk kedalam uji coba media dengan menilai tingkat pemahaman mahasiswa terhadap materi sebelum menggunakan media dan setelah menggunakan media yang dibuat, sebanyak 15 butir soal yang dijawab oleh mahasiswa dengan bentuk soal pilihan ganda, adapun hasilnya sebagai berikut.

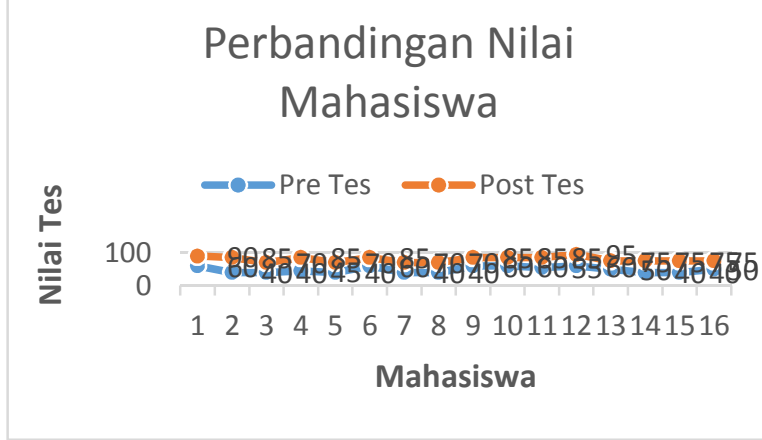

Gambar 4. Diagram hasil belajar mahasiswa

Sedangkan jika dilihat secara keseluruhan rata-rata nilai mahasiswa antara pre tes dan post tes, hasil prestasi belajar yang diperoleh mahasiswa dengan menggunakan media 
pembelajaran mengalami peningkatan sebesar \pm 64 poin, seperti terlihat pada gambar dibawah ini.

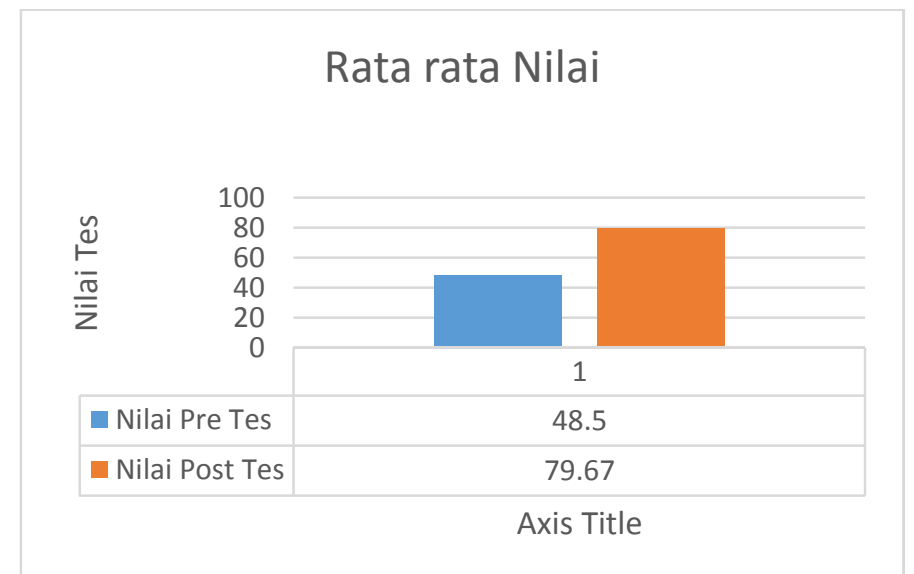

\section{Gambar 5. Perbandingan Rata-rata nilai Pre Tes \& Post Tes}

Dari hasil belajar diatas dapat dilihat bahwa dengan menggunakan media pembelajaran alignment pulley dan kopling dengan metode laser dan dial indicator apabila di persentasekan mengalami kenaikan sebesar 63\% dan adapun hasil pengujian untuk menilaai adanya peningkatan yang signifikan dari hasil belajar mahasiswa dapat kita lihat berdasarkan hasil uji $\mathrm{t}$ dengan menggunakan aplikasi SPSS dibawah ini.

Tabel 2. Perbedaan nilai Pre tes dan Post tes berdasarkan nilai rata-rata Paired Samples Statistics

\begin{tabular}{|ll|c|c|c|c|}
\hline & & Mean & $\mathrm{N}$ & Std. Deviation & Std. Error Mean \\
\hline \multirow{2}{*}{ Pair 1 } & Pre Test & 48.75 & 16 & 9.037 & 2.259 \\
& Post Test & 79.69 & 16 & 8.056 & 2.014 \\
\hline
\end{tabular}

Untuk nilai pre test diperoleh nilai rata-rata hasil belajar sebesar 48.75. Sedangkan untuk nilai post test diperoleh nilai rata-rata hasil belajar atau Mean sebesar 79.69. Karena nilai rata-rata (Mean) hasil belajar pada post test $79.69>$ dari pre test sebesar 48.75, maka itu dapat diartikan bahwa secara deskriptif ada perbedaan rata-rata hasil belajar antara pres test dengan post test. Jumlah responden atau mahasiswa yang digunakan sebagai sampel penelitian adalah sebanyak 16 mahasiswa. Untuk nilai standar deviation pada pre test sebesar 9.037 dan Post test sebesar 8.056. Nilai Std. Error Mean sebesar 2.857 untuk pre test dan untuk post test sebesar 2.014.

Tabel 3. Korelasi atara Hasil Pretest dan Posttest Paired Samples Correlations

\begin{tabular}{|ll|c|c|c|}
\hline & $\mathrm{N}$ & Correlation & Sig. \\
\hline Pair 1 & Pre Test \& Post Test & 16 & .773 & .000 \\
\hline
\end{tabular}

Tabel di atas menunjukkan hasil uji korelasi atau hubungan antara kedua data atau hubungan variabel Pre Teste dengan variabel Post Test. Berdasarkan tabel output di atas diketahui nilai koefisien korelasi sebesar 0.773 dengan nilai signifikansi (Sign.) sebesar 0.000. Karena nilai Sign. $0.000<$ dari 0.05 maka dapat dikatakan ada hubungan antara variabel Pre Test dengan variabel Post Test.

Tabel 4. Tabel Nilai Signifikansi Paired Samples Test

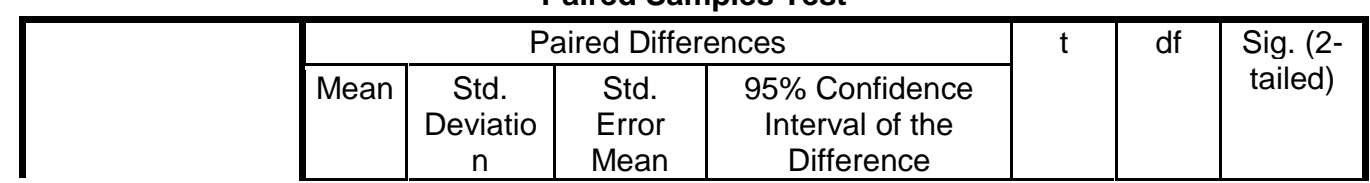




\begin{tabular}{|c|c|c|c|c|c|c|c|c|c|}
\hline & & & & & Lower & Upper & & & \\
\hline $\begin{array}{l}\text { Pai } \\
\text { r } 1\end{array}$ & $\begin{array}{l}\text { Pre Test - } \\
\text { Post Test }\end{array}$ & $\begin{array}{r}30.93 \\
8\end{array}$ & 5.836 & 1.459 & -34.047 & -27.828 & $\begin{array}{r}21.20 \\
3\end{array}$ & 15 & .000 \\
\hline
\end{tabular}

Berdasarkan tabel output Paired Samples Test di atas, dapat dilihat nilai Sign. Sebesar 0.000 $<0.05$, maka dapat disimpulkan bahwa ada perbedaan rata-rata antara hasil belajar Pre Test dengan Post Test yang artinya terdapat pengaruh penggunaan penggunaan media pembelajaran praktik alignment pada pully dan kopling dengan menggunakan metode cahaya laser dan dial indicator. Ini menunjukkan bahwa pengembangan media pembelajaran Alignment pada Pully dan Kopling menggunakan metode cahaya laser dan dial indikator pada Mata Kuliah Praktik Alignmet telah meningkatkan pemahaman mahasiswa. Tabel ouput di atas juga menunjukkan nilai Mean Paired Differences sebesar -30.938. Nilai tersebut menunjukkan selisih antara rata-rata hasil belajar Pres Test dengan rata-rata hasil belajar Post Test dan selisih perbedaan tersebut antara -34.047 sampai dengan -27.828 .

\section{Kesimpulan}

Kesimpulan yang diperoleh dari hasil penelitian ini antara lain adalah: (1) Media pembelajaran alingment pada pulley dan kopling dengan metode laser dan dial indicator sangat efektif dalam meningkatkan prestasi belajar dan pemahaman mahasiswa terkait alingnment, yang dimana rata-rata peningkatan prestasi belajar mahasiswa sampai $63 \%$. (2) Adanya pebedaan nilai hasil analisis statistik dengan menggunakan SPSS dimana nilai ratarata Post Test $79.69>$ dari Pre Test sebesar 48.75, sedangkan pada paired sample correlations nilai Sign. $0.000<$ dari 0.05 maka dapat dikatakan ada hubungan antara variabel Pre Test dengan variabel Post Test dan Paired Samples Test Sebesar $0.000<0.05$, maka dapat disimpulkan bahwa ada perbedaan rata-rata antara hasil belajar Pre Test dengan Post Test yang artinya terdapat pengaruh penggunaan penggunaan media pembelajaran praktik alignment pada pully dan kopling dengan menggunakan metode cahaya laser dan dial indikator.

\section{Saran}

Saran yang dapat disampaikan berdasarkan hasil penelitian ini, yaitu: 1) Kepada Mahasiswa diharapkan untuk menggunakan Media pembelajaran Alignment dengan baik agar menjadi bekal pengetahuan yang dapat dimanfaatkan disaat memasuki dunia industri; 2) Kepada Dosen Program Studi Perawatan dan Perbaikan mesin agar dapat memanfaatkan media pembelajaran Alingment dalam proses belajar mengajar serta dapat melanjutkannya untuk penelitian pengembangan dimasa yang akan datang, dan 3) Kepada Politeknik Bosowa diharapkan dapat melakukan kerjasama dengan pihak industri untuk melakukan penyempurnaa dan pengembangan media pembelajaran alingment.

\section{Daftar Pustaka}

Azwar, S. (2013). Reliabilitas dan Validitas. Yogyakarta: Pustaka Pelajar.

Darmawan, dkk (2016). Misalignment Kopling dengan analisis sinyal getaran kondisi Steady state menggunakan metode reverse.Jurnal teknik mesin S1,Vol 4(2),197-206, http://ejournal-s1.undip.ac.id/index.php/jtm

Darto \& Sudjatmiko. (2015) Mekanisme Proses Alignment Poros Mesin Rotasi Berbantu Perangkat lunak, Jurnal info teknik, Vol 16 (1),11-20 
Dodi Budi Laksono, h.r. (2018). Rancang Bangun Media Pembelajaran Setting Alignment. Jurnal teknologi dan terapan bisnis, 1 ,38-43.

Kd.Ayuning R, dkk (2016). Analisis Faktor-Faktor Yang Mempengaruhi hasil Belajar Bahasa Indonesia pada siswa Kelas V Sd Gugus VI. e-Journal PGSD Universitas Pendidikan Ganesha Jurusan PGSD Vol: 4 No: 1 Tahun: 2016. https://ejournal.undiksha.ac.id/index.php/JJPGSD/article/viewFile/7454/5081

Lifetime Reliability Solution. (2012). Precision Maintenance Tehniques For Machinery. Machine Installation-Shaf Alignment, hal. 17.

Mulyatiningsih, E. (2013). Metode Penelitian Terapan Bidang Pendidikan. Bandung: Alfabeta.

Nunu M (2012). Kajian Terhadap langkah-langkah pemilihan media dan implementasinya dalam pembelajaran, Jurnal Pemikiran Islam; Vol. 37, No. 1 Januari-Juni 2012. http://ejournal.uin-suska.ac.id/index.php/Anida/index.

Rudi Susilana, C. R. (2011). Media Pembelajaran: Hakikat, Pengembangan, Pemanfaatan, dan Penilaiaan. Bandung: CV. Wacana Prima.

Sugiyono. (2019). Metode Penelitian Pendidikan. Bandung: Alfabeta.

Suharsimi. (2011). Prosedur penelitian: Suatu Pendekatan Praktik. Jakarta: Rineka Cipta.

SKF. (2012). Rolling Bearings. Shutterstock.

Sukoco, Bhimo dkk. (2019). Pemahaman Pendidikan Vokasi Di Jenjang Pendidikan Tinggi Bagi Masyarakat. Jurnal Pendidikan Vokasi, Vol 1, No 1, http://ejournals1.undip.ac.id/index.php/jtm.

Tafanao, Talozaro. (2018). Peran Media Pembelajaran Dalam Meningkatkan Minat Belajar Mahasiswa. Jurnal Komunikasi Pendidikan, Vol 2, No 2, http://journal.univetbantara.ac.id/index.php/komdik/article/view/113/0.

Tauvana Irvan A (2018). Alignment Kopling dengan metode double dial indicator rim and face. Jurnal Simetris, Vol 9 No 1, https://jurnal.umk.ac.id/index.php/simet/index

Undang-Undang Sistem Pendidikan Nasional. (2013). PP No.20 Tahun 2003. Jakarta: Sinar Grafika. 